ous amici schools and organizations, can see extreme instances where the law may apply (for example, if falsification of clinical trial data on some drug or vaccine led to the government spending huge sums on that treatment, and the government itself claimed that it had been harmed). But they also argue that Berge $v$. University of Alabama, Birmingham, is not such a case.

Berge's suit is not the first researchrelated case brought under the qui tam provisions of the False Claims Act. In 1994, the University of Utah and the University of California settled the first such case out of court for $\$ 1.575 \mathrm{mil}$ lion, although they denied charges of misconduct, saying that problems with the research were rather due to "sloppiness" on the part of the John Ninnemann, the researcher accused of misconduct by Thomas Condie, one of his former colleagues. Condie alleged that Ninnemann had made false claims in papers and in his grant applications, and that the University of Utah and, later, the University of California (where Ninnemann relocated) "allowed" him to make these claims, thus defrauding the US government. Unlike the Berge case, the Department of Justice joined in the prosecution of the Condie case.

Another closely watched qui tam suit was dismissed last October by another judge in the same federal Court in Maryland in which the Berge case was heard. In this case, Kathryn Milam, a postdoctoral researcher at the University of California at San Francisco (UCSF), alleged that her inability to reproduce results obtained by UCSF researchers in the early 1980 s (and used to gain federal grant money) indicated fraud on the part of the researchers. The judge turned the case down, saying that it was "a legitimate scientific dispute, not a fraud case."

Although only one other qui tam case is scheduled for jury trial later this year, it is suspected that several other cases are on the horizon. But no one outside of the Department of Justice knows how many research-related qui tam cases are pending, because qui tam suits are under seal for at least sixty days to allow the Department of Justice time to decide whether to join the plaintiff in prosecuting the case. But the general wisdom holds that the number is increasing, and will do so exponentially if the jury's verdict in the Berge case is allowed to stand.

The response of Berge's lawyers (who were unwilling to discuss the case) and any amici briefs in her favor (including a US government brief defending the constitutionality of qui tam) are due June 21. Following a response by the UAB lawyers and oral arguments, a decision from the Court of Appeals is expected by the end of the year. Although it is impossible to say how the judge will view the appeal, one thing is certain: if the Berge verdict stands, it could have dire consequences for any research institution receiving government money.

FINTAN R. STEELE

\title{
Middle East countries unite against common enemy
}

Israel and its neighbors have launched their first joint governmental effort in the area of medicine. On May 20, they signed an agreement to form the Middle East Cancer Consortium (MECC), which includes Cyprus, Egypt, Israel, Jordan and the Palestinian Authority. The United States, particularly its National Cancer Institute $(\mathrm{NCl})$, played a major role in the establishment of the new body and provided the initial sum of US $\$ 1.8$ million for the start of its operation. Consortium members will provide at least as much in funding, although individual levels have yet to be established.

The goal of the Consortium is to improve health care and promote scientific collaboration in the field of cancer in the Middle East, while setting up a model for increased regional cooperation in other areas. This is one of the first projects to involve so many Middle Eastern countries that three years ago "couldn't have even dreamed of coming together to discuss a joint undertaking," says Michael Silbermann, Chief Scientist at Israel's Ministry of Health and the Israeli representative to MECC. "I hope we do not stop at six members and include new countries - first of all those that already have some kind of relations with Israel, such as Morocco and Tunisia, and who knows, perhaps also Oman and Qatar," he said. Silbermann also said the recent change of government in Israel should have no effect on the work of the consortium.

Among the first tasks on the MECC agenda is creation of cancer registries, particularly in countries where cancer statistics are scarce. These can provide a basis for epidemiological studies, investigations into the effects of lifestyle on cancer development and other types of scientific research. For example, the Egyptians are particularly interested in finding out why bladder cancer is the most common type of malignancy among Egyptian males, a question that is also of interest to the scientific and medical community worldwide, ac- cording to Silbermann. Intriguing insights into breast cancer may also emerge from regional cooperation, as in some Middle Eastern countries this disease has peculiar patterns. In most parts of the world this malignancy affects women over 50, but in Egypt this cancer primarily strikes younger women. "At the level of molecular genetics, we must see if in this case we are always talking about the same disease," Silbermann said.

Another important task is improving standards of care, according to oncologist Eliezer Robinson, chairman of the Israel Cancer Association, who heads the quality control commission of the MECC. The commission is conducting a survey of personnel, equipment and practices in the treatment of cancer by MECC members.

Cancer information and education efforts will play an important role in MECC activities, as well as improving the expertise of personnel. $\mathrm{NCl}$ will provide stipends for researchers, physicians and other health care professionals from the Middle East to receive training either at $\mathrm{NCl}$ itself or affiliated institutions.

Cancer was chosen as the focus of the consortium because cooperation in this area had already existed in the region, according to Yosef Baratz, head of the International Relations Department at Israel's Ministry of Health. By 1994 oncologists of the area had already formed the Middle East Cancer Society, a nongovernmental organization now headed by an Egyptian physician. Contrasted with the society's major activities of scientific collaboration, the new consortium will provide political and financial backing for such international efforts, Baratz said.

The first meeting of the MECC board of governors is expected to be held in Israel in the beginning of July.

LUBA VIKHANSKI Tel Aviv, Israel 